\title{
Computer model for Vedavati ground water basin. Part 2. Regional model
}

K SRIDHARAN, N S LAKSHMANA RAO, M S MOHAN KUMAR and V RAMESAM*

Department of Civil Engineering, Indian Institute of Science, Bangalore 560012 , India

* Central Ground Water Board, 2, 36th Cross, 8th Block, Jayanagar, Bangalore 560082, India

MS received 6 March 1984; revised 23 August 1985

\begin{abstract}
A computer model for regional ground water resource evaluation, based on the leaky aquifer concept, is presented for the Vedavati basin which is a crystalline hard rock area of $24,200 \mathrm{~km}^{2}$ in Peninsular India. The model can handle nonhomogeneity, anisotropy, varied pumping, rainfall and river stages. The model is calibrated based on regional water level observations for one year. The calibrated model is used to determine the distribution of safe yield, overexploited regions and regions of maximum potential over the basin. Regions which are most affected by drought conditions are also identified.
\end{abstract}

Keywords. Ground water; regional model; computer model; hard rock; leaky aquifer.

\section{Introduction}

The validity of a leaky aquifer model for the hard rock ground water system of the Vedavati river basin was discussed in Part 1 (Sharma et al 1986). The interstate basin

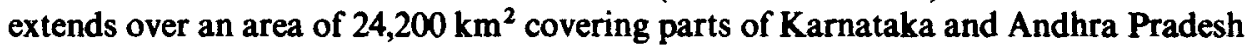
states. The Vedavati basin is a typical crystalline hard rock area, comprising granite/gneiss and schist regions. From an analysis of the well field observations, it was concluded that a modified leaky aquifer concept, in which the entire weathered and clayey zone above the deeper fracture-aquifer is treated as a composite unconfined aquitard, can be used to represent the hard rock aquifer system (figure 5 of Part 1).

The development and application of a computer model for ground water resource evaluation in the entire basin area is presented in this part. 


\section{Basic equations}

The basic differential equation for the aquifer is given by

$$
\frac{\partial}{\partial x}\left(T_{x} \frac{\partial h}{\partial x}\right)+\frac{\partial}{\partial x}\left(T_{y} \frac{\partial h}{\partial y}\right)=S \frac{\partial h}{\partial t}-C_{L}\left(h^{\prime}-h\right)+Q^{\prime}
$$

In (1), $x$ and $y$ are along the principal directions which are identified as northeastsouthwest and northwest-southeast based on the major directions of fractures. The leakage from the watertable zone (aquitard) to the fractures (aquifer) is taken to be proportional to the head difference and the leakage coefficient $C_{L}$. If the lateral flow in the watertable zone can be ignored, the differential equation (approximate) governing the variation of the watertable head may be written as

$$
S^{\prime} \frac{\partial h^{\prime}}{\partial t}+C_{L}\left(h^{\prime}-h\right)-Q_{I}=0
$$

Equations (1) and (2) are to be solved subject to the relevant initial and boundary conditions. The initial conditions correspond to the known distribution of piezometric head in the entire basin at a specified time. The boundary conditions are the no-flow conditions across the boundary of the basin. In addition to these, the river acts as an internal boundary with specified variations of water levels. In view of the nonhomogeneity of the parameters, (1) and (2) have to be solved numerically using a digital computer.

\section{Features of the model}

\subsection{Discretisation of the aquifer}

A square finite difference grid of $5 \mathrm{~km}$ size is superimposed on the aquifer plan (figure 1). A grid point approximation of the basin boundary is made as shown in figure 1. For the sake of convenience, the computational region is made rectangular enclosed by the lines $i=1, i=58, j=1, j=40$ in figure 1 . However, the nontrivial computations are made only for the region within the aquifer boundary and this is achieved by setting the transmissivity values $T_{x}$ and $T_{y}$ at zero outside the flow boundary (Prickett \& Lonnquist 1971; Trescott \& Larson 1977). Such a procedure also satisfies the no-flow condition at the aquifer boundary.

\subsection{Block structure of the model}

Modelling the entire area of $24,200 \mathrm{~km}^{2}$ with a moderate grid size of $5 \mathrm{~km}$ requires modifications to reduce the computer memory requirements if the programme has to run on moderate size computers. The dummy region used outside the actual aquifer boundary to make the solution region rectangular for computational convenience, accentuates the problem of memory requirement. For a leaky aquifer model, there are six parameters $-T_{x}, T_{y}, S, S^{\prime}, C_{L}$ and $F_{i}$, a recharge index. Besides these, there are other variables to be defined at each node such as the present and the previous piezometric heads in the aquifer, watertable head, rainfall and pumped discharge. 


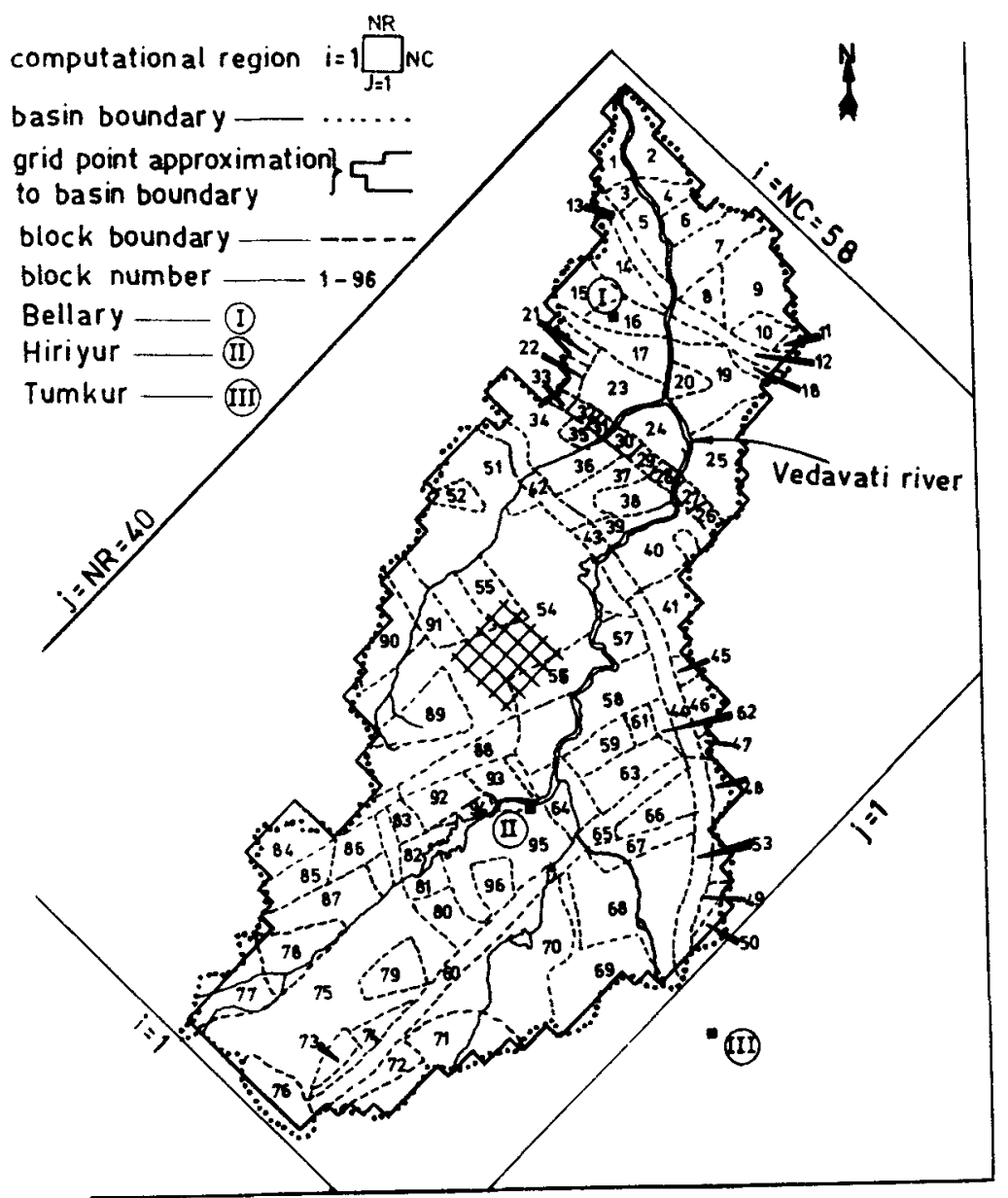

Figure 1. Discretisation structure for finite difference model

The problem associated with very large computer memory requirements is eliminated in the present model by zoning the entire basin into 96 blocks based on hydrogeological characteristics (figure 1). Each block is effectively treated as homogeneous so that inputs such as the storage coefficient, transmissivity, leakage coefficient and rainfall are the same at all nodes within the block. With one default block for the dummy nodes outside the aquifer boundary, there are in all 97 blocks for the 2320 nodes. The nonhomogeneity of the aquifer is represented by the variations of properties between the blocks. Besides saving computer memory requirements very significantly, this block representation is also more realistic in view of the limitations of the availability of data on a node to node basis. 


\subsection{Anisotropy}

Based on well field observations, it was inferred that the granite regions are nearly isotropic while the schist regions have a pronounced anisotropy with a larger transmissivity in the northwest-southeast direction (Part 1). From an analysis of the pump test data, a value of $T_{y}=5 T_{x}$ was adopted for the schist regions while a value of $T_{y}=T_{x}$ was used for the granite/gneiss regions. The schist region forms only $20 \%$ of the basin area (blocks $4,18,21,70,77,88,89,91$ to 96 ; vide figure 1 ).

\subsection{Conditions at the river nodes}

At the river nodes, both the aquifer and the water-table aquitard heads were taken to be the same and equal to the river stage. The river stage changes with both time and space and these changes are to be fed into the model as data. While the river stage actually determines the aquifer heads at the river nodes, the iterative algorithm used in the numerical solution of the partial differential equation requires that heads must be computed at all the nodes including the river nodes. This difficulty is, however, overcome by 'computing' the heads at river nodes also, in such a way that the aquifer and the watertable heads would equal the river stage. This is achieved by writing the equation at the river nodes as

$$
\mathrm{d} h / \mathrm{d} t=f\left(N_{r}, t\right),
$$

where $N_{r}$ is the number of the particular river node identifying the location along the river. The right side of (3) gives the rate of change of river stage as a function of location and time, and is provided as data.

\subsection{Input for temporally varying data}

Three of the essential inputs for the computations - the rainfall, the river stage and the quantity of pumping - vary with time. To give a proper input for these variables, the total time for which computations are to be made is divided into $N_{T}$ intervals and data is provided for each interval. There is provision to provide periodic data also.

\subsection{Estimate of recharge}

The recharge term in (2) should be actually the net recharge after deducting ground water evapotranspiration. Evapotranspiration may affect only those regions where ground water occurs at shallow depths of less than $5 \mathrm{~m}$ and hence it may be relatively insignificant over most of the Vedavati basin aquifer. Ground water evapotranspiration and irrigation returns are only implicitly taken into account through model calibration.

The recharge term is expressed in the model as a fraction of rainfall. It is nonhomogeneous being different for different blocks. The recharge factor as a fraction of rainfall may in reality depend on the magnitude of rainfall. In the present study, the recharge factors are obtained by calibrating the model based on water level observations during the period November 1977 to November 1978, in which the rainfall was close to normal. 
The net recharge during the nonmonsoon periods is assumed to be zero as off-season rainfall may not be adequate even to fully satisfy the soil moisture requirements.

\section{Finite difference solution}

The finite difference analogue of (1) at any grid point $(i, j)$ for a square grid $\Delta x=\Delta y$, is given by (figure 2)

$$
\begin{aligned}
& -\left(T_{y}\right)_{i, j-1} h_{i, j-1}-\left(T_{x}\right)_{i-1, j} h_{i-1, j}+\left[\left(T_{y}\right)_{i, j-1}+\left(T_{x}\right)_{i-1, j}\right. \\
& \left.+\left(T_{x}\right)_{i, j}+\left(T_{y}\right)_{i, j}+S_{i, j}\left(\Delta x^{2} / \Delta t\right)+\left(C_{L}\right)_{i, j} \Delta x^{2}\right] h_{i, j} \\
& -\left(T_{x}\right)_{i, j} h_{i+1, j}-\left(T_{y}\right)_{i, j} h_{i, j+1}=S_{i, j}\left(\Delta x^{2} / \Delta t\right) h_{i, j}^{0}-Q_{i, j} \\
& +\left(C_{L}\right)_{i, j} \Delta x^{2} h_{i, j}^{\prime}
\end{aligned}
$$

In (4), $Q_{i, j}=Q_{i, j}^{\prime} \Delta x^{2}$, which is the total pumping at node $(i, j)$. If (4) is written for the $N_{C} \cdot N_{R}$ nodes, there is a set of $N_{C} \cdot N_{R}$ linear algebraic equations for $h_{i, j}$ values. Strictly, as the watertable head values $h_{i, j}^{\prime}$ on the right side of (4) are also unknowns, a two-level iteration procedure is called for. However, computations show that $\boldsymbol{h}_{i, j}^{\prime}$ values may be taken from the already computed values at time $t$.

The $N_{C} \cdot N_{R}$ equations formed by (4) are to be solved by an iterative method. Though it is now established (Stone 1968; Trescott \& Larson 1977) that the strongly implicit procedure (SIP) is the best method for solving such a system of equations, the alternating direction implicit (ADI) method is used in the present study. The method used is a modified version of the classical ADI method (Nallasamy 1975). Doubts have been expressed about the utility of the ADI method for anisotropic problems (Remson et al 1971). However, preliminary computations for well field problems (Part 1; Manvinder Singh 1978) established the adequacy of the ADI method for the present problem. In all the regional studies made, the convergence characteristics of the ADI method was good. It must be noted that difficulties are felt with the ADI method (Trescott \& Larson 1977) when used in more critical problems involving steady state solutions. A good starting solution for the iterative procedure is easily obtained for the unsteady state problems. In the present model, the quadratic predictor recommended by Prickett \& Lonnquist (1971) is used.

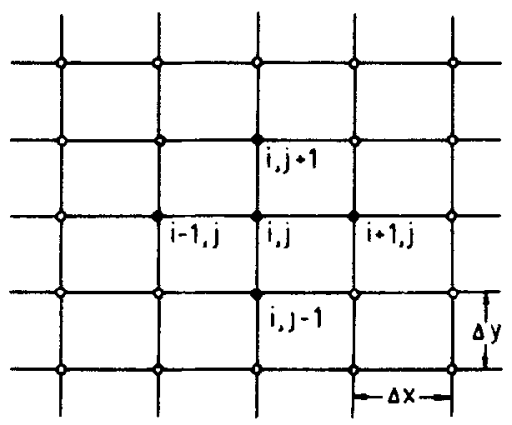

Figure 2. Definition sketch for finite difference equation. 
Once the aquifer heads are computed by the ADI method, the watertable head in the aquitard zone is computed from a finite difference approximation of (2). The final equation obtained for the watertable head is

where

$$
\begin{aligned}
h_{i, j}^{\prime}= & h_{i, j}^{\prime 0}+B_{i, j}\left(C_{L}\right)_{i, j}\left(h_{i, j}+h_{i, j}^{0}-2 h_{i, j}^{\prime 0}\right) \\
& +2 B_{i, j}\left(F_{i}\right)_{i, j}\left(R_{f}\right)_{i, j},
\end{aligned}
$$

$$
B_{i, j}=\left(\Delta t / S_{i, j}^{\prime}\right)\left\{1 /\left[2+\left(C_{\nu}\right)_{i, j} \Delta t / S_{i, j}^{\prime}\right]\right\}
$$

Once the aquifer and watertable heads are computed for time $t+\Delta t$, the solution is advanced to the next time step $t+2 \Delta t$ after updating the values of $h^{0}$ and $h^{\prime 0}$.

\section{Calibration of the model}

\subsection{Need for calibration}

Aquifer parameters such as transmissivity, storage coefficient, specific yield and leakage coefficient are normally estimated from pump test observations. However, due to limitations of resources, pump tests are feasible only at a limited number of locations. Besides, there is always a tendency to select locations which are likely to yield substantial quantities of water in drilling wells for pump tests and other investigative studies, so that these test wells may be converted to production wells later. While such a procedure is understandable, the tests, however, would lead to unrepresentative values for determining the aquifer parameters for a regional study. Thus data from pump tests, while highly useful for studies on a local scale, have both quantitative and qualitative limitations for application on a regional scale. It is because of this that model calibration is done based on observations of water levels on a regional scale.

\subsection{Aquifer parameters and draft}

The calibration of the model was done based on field observations of water levels for a one-year period starting from November 1977. The initial inputs of parameters as the starting values for the calibration were provided by the probject team of the Central Ground Water Board based on long duration pump tests, short duration air tests, water level observations over the entire basin and local and regional hydrogeological considerations.

For a proper calibration of the model, a good estimate of the distribution of the existing draft is necessary. Determination of the draft for such a large area of $24,200 \mathrm{~km}^{2}$ is a very difficult task as there is no alternative but to resort to indirect methods. Four different methods were used: (i) enumerating the wells, classifying them and associating one specific discharge for each type of well based on selected field observations; (ii) using the above procedure with a slight modification wherein the horse power of the motor and pump head are considered in determining the discharge for each well driven by electric motors; (iii) estimating the draft based on irrigation and domestic water requirements using data on crop area, population etc.; (iv) using the electricity consumption as a guide for estimating the distribution of draft.

These methods gave a variation of $\pm 18 \%$ in the estimated draft, which, considering the total area involved and the indirect nature of the methods, is not a very large 
difference. The average of these estimates indicates that the total annual draft for the entire basin is $548 \times 10^{6} \mathrm{~m}^{3}$ (m cu m) ${ }^{\dagger}$. It was also estimated that with respect to the annual average, pumping is $\mathbf{4 0} \%$ excessive during February to May, $10 \%$ excessive during October to January and $50 \%$ deficit during June to September.

\subsection{Initial conditions}

The model requires the aquifer and the water-table heads to be specified at the start of the simulation period. Thus, for the calibration studies, it is necessary to specify the values of $h_{i, j}$ and $h_{i, j}^{\prime}$ in November 1977 for all the nodes within the basin. Water level observations in 508 key observation wells were used to obtain the watertable head values at all the nodes. The aquifer head values were estimated from the watertable head values using the difference between the watertable and the deeper aquifer heads as observed at piezometric locations in the entire basin. The difference between the watertable and the aquifer heads is less than $1 \mathrm{~m}$ over most parts of the basin.

\subsection{Calibration process}

The problem of model calibration reduces to the modification of the parameters $T_{x}, T_{y}$, $S, S^{\prime}, C_{L}$ and $F_{i}$, for all the 96 blocks to get the best agreement with field observations of water level variations during the period November 1977-November 1978. It becomes necessary to use the watertable head only for evaluating the results because available piezometric observations are so scanty as to make it impossible for any verification on a regional scale. However, this is not a serious disadvantage for the regional model as, when pumping is averaged out on a regional scale, the computed results show that the difference is not very much between the watertable and the deeper aquifer heads.

The adjustments of parameters were initially made by a sequence of sensitivity studies. Finer adjustments were made on a block to block basis based on the results of the sensitivity studies. After some preliminary computations with time steps of 5 and 10 days, a time step of 10 days was used for most of the subsequent computations.

\subsection{Parameter values for the calibrated model}

Computations showed that even a moderately large variation in the transmissivity values did not affect the results of regional simulation significantly. An order of magnitude study of the terms of the governing equation (1) confirmed this, as the flow term was found to be much smaller than the leakage or storage terms for regional simulation studies. This is not to say that errors in the estimate of transmissivity values are not important. But such errors, in view of the relatively small values of transmissivity in hard rock aquifers, do not introduce significant errors in a regional study of the present scale. However, a good estimate of transmissivity values is important in the study of local ground water flow in the vicinity of a well. For the regional model, the transmissivity values as estimated initially were directly adopted.

Unlike the transmissivity values, changes of storage coefficient, specific yield, leakage coefficient and recharge factor affected the results significantly, though with varying influence. The final values of the storage coefficient obtained through model calibration are in the range of 0.2 to 1.0 times, the leakage coefficient values in the range of 0.1 to 5.0 times, the specific yield values in the range of 0.50 to 1.33 times, and the recharge factor values in the range of 0.50 to 1.33 times the initial estimates. $T_{x}$ and $T_{y}$ range from 
$1 \mathrm{~m}^{2} /$ day to $350 \mathrm{~m}^{2} /$ day, $S$ from 0.00001 to $0.001, S^{\prime}$ from 0.005 to $0.04, C_{L}$ from $0.0001 /$ day to $0.0005 /$ day and $F_{i}$ from 0.03 to 0.15 , among the 96 blocks.

\subsection{Comparison of computed results with field observations}

In order to assess the validity of the calibrated model, the average of the difference in water levels between November 1978 and November 1977 at all the nodes in each block (figure 1) is compared with the corresponding field observations at all the key observation wells in the same block. A comparison of the computed results and field observations for the water level variations is presented in figure 3. It is seen that over most parts of the basin, there is good agreement between computed results and field observations. A quantitative idea of the agreement between computed results and field observations is provided by the error norm,

$$
E=\left[\sum_{i=1}^{N_{B}}\left(e_{i}\left(A_{i} / A_{T}\right)\right)^{2}\right]^{1 / 2} .
$$

The norm $E$ is calculated separately for the $65 \%$ of the basin area over which $e_{i}$ is less than $1 \mathrm{~m}$ (figure 3 ) and for the entire basin area. These values are $0.07 \mathrm{~m}$ and $0.21 \mathrm{~m}$ respectively.

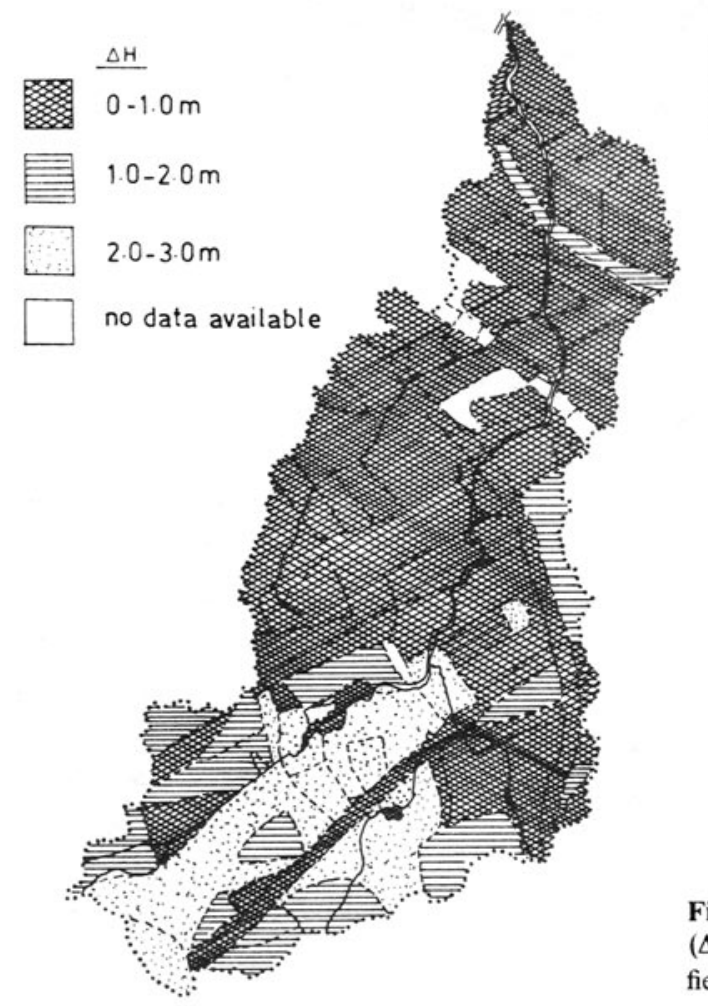

Figure 3. Comparison for water level variations $(\Delta \mathrm{H}=$ difference between computed results and field observations). 


\section{Safe yield of the basin}

\subsection{Methodology}

One of the most important applications of the calibrated model is the determination of the safe yield. Safe yield is defined as the maximum rate of withdrawal from the ground water reservoir which, in the long run, does not produce any significant decline of the water level. Thus safe yield is the long term average net annual recharge from all sources such as rainfall, river, irrigation return flow, canals and tanks.

The distribution of the safe yield was first determined based on the average annual rainfall input for each block. The initial estimates of the safe yield provided by the Central Ground Water Board were modified in stages based on several computer

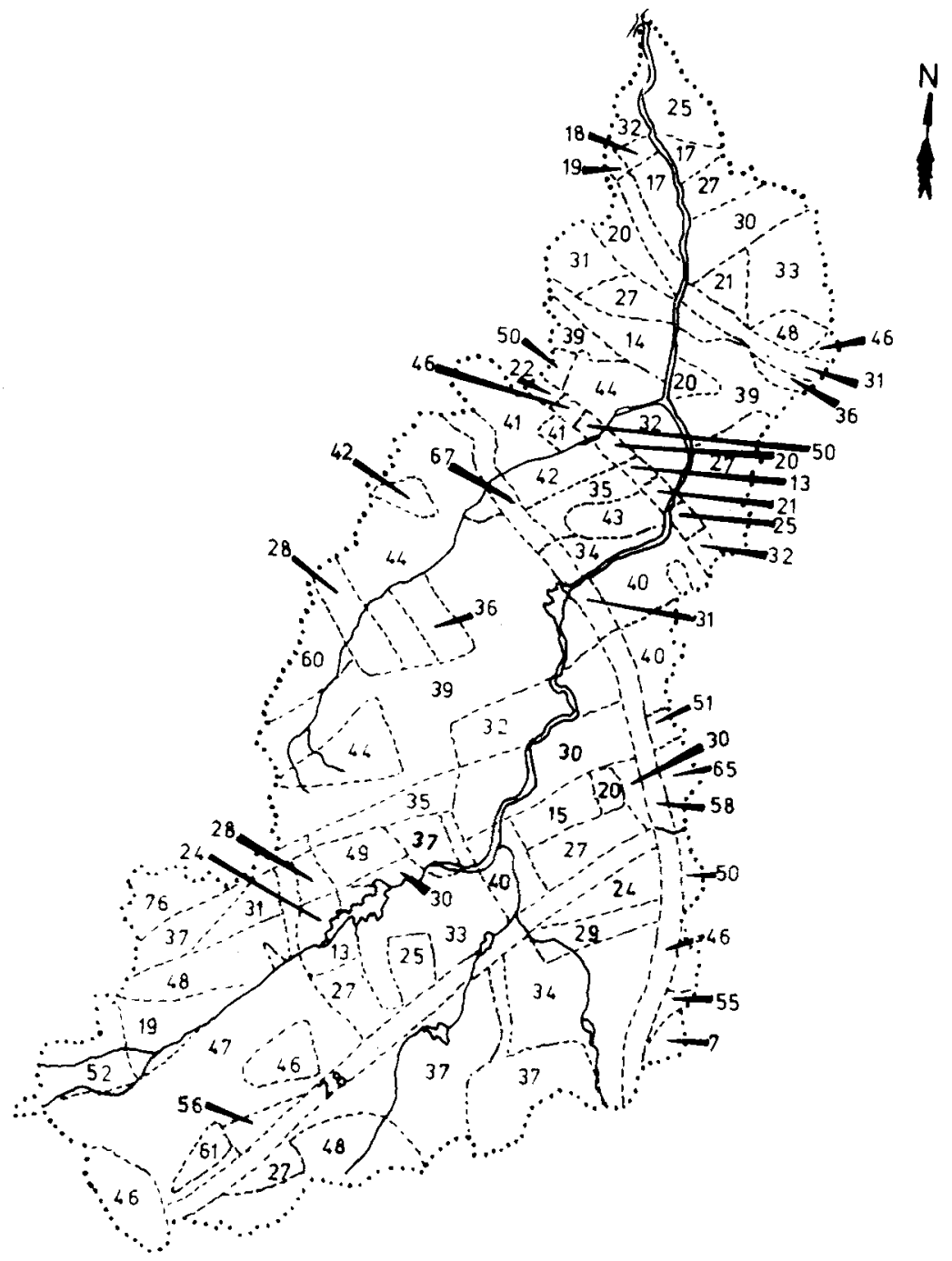

Figure 4. Blockwise estimates of safe yield (numbers inside the blocks give the annual safe yield values in millimetres). 
outputs. The aim was to ensure that the average annual variation of water level over each block does not exceed $0.1 \mathrm{~m}$. The effect of varying the pumping rate in different months was also studied. In order to study the effect of pumping at the safe yield rates under varied rainfall inputs, computer simulations were made for a 20-year period with homogeneous and nonhomogeneous variations of rainfall over the basin.

\subsection{Estimates of the safe yield}

The values of the safe yield for all the 96 blocks as obtained from the computer model are presented in figure 4. It is believed that these estimates do not include the effect of local factors such as recharge from canals and irrigation tanks. This is because the area over which such recharge occurs is very limited and key observation wells, which form the basis of data for calibration, are not generally located in the vicinity of canals and tanks.

The safe yield for the entire basin as presented in figure 4 works out to $910 \mathrm{~m} \mathrm{cu} \mathrm{m}$. The project team of the Central Ground Water Board estimated the total annual recharge from canals and tanks as $230 \mathrm{~m}$ cu m. Thus the total potential of the basin works out to $1140 \mathrm{~m} \mathrm{cu} \mathrm{m}$.

One interesting observation may be made from the results presented in figure 4 . It is found that the safe yield values are not particularly high in the valley portions. In the estimation of the safe yield for the blocks adjacent to the river, it was stipulated that the annual drawdown at the nodes other than the river nodes, should not be large. The relatively moderate safe yield in the valley portions is perhaps explained by the flow term being small.

\subsection{Distribution of critical and undeveloped regions}

A comparison of the safe yield estimates in figure 4 with the estimates of the existing draft enables identification of the critical regions where ground water is being overexploited and regions where maximum ground water development is possible. The distribution of these regions over the basin is presented in figure 5 .

The model studies show that there are some overexploited regions in the central and southeast parts of the basin. The project team of the Central Ground Water Board independently inferred from field observations that there are some over exploited areas and the areas identified by them are also shown in figure 5. It is seen that except for some small patches of areas, the critical areas identified by the project team fall in the two categories of regions presented in figure 5, where the model indicates overexploitation or no scope of development.

It is seen from figure 5 that moderate to good development potential is indicated over substantial parts of the upper and lower reaches of the basin, while in the central parts, the potential regions are confined to the uplands.

\subsection{Effect of drought on ground water}

Pumping as per the safe yield estimates should not lead to any significant decline of water levels on a long term basis. However, it would be useful to know the magnitude of the water level decline under drought conditions and whether such a decline is to an unacceptable extent in any region. The drawdown in the deeper aquifer is of particular 


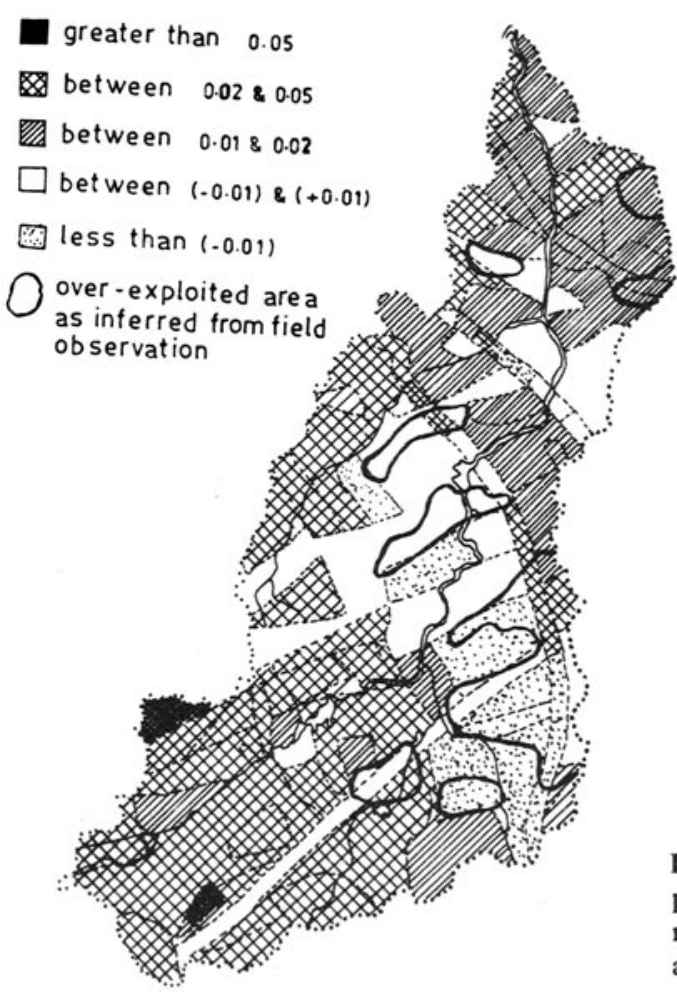

Figure 5. Overexploited areas and areas for potential development (numbers indicate in metres the difference between annual safe yield and existing annual draft).

interest in finding out whether any region of the aquifer gets converted to an unconfined system.

Different simulation studies were made to study the effect of drought. The simulation studies covered a period of six years with moderate to severe drought for two successive years. The impact of a one-year severe drought is taken as a guide in identifying areas in which piezometric head declines are severe in relation to allowable drawdown. The distribution of such areas is presented in figure 6. It is seen that the areas most affected by drought conditions are concentrated in the upper reaches and the uplands of the central reaches. It was seen (figures 1 and 5) that block no. 84 on the southwest boundary of the basin has good potential for development. But this area is also found to be most vulnerable to drought conditions (figure 6) which might affect the development potential of the area.

\section{Conclusions}

A computer model for regional ground water resource evaluation has been developed for a fractured rock aquifer system. The model is based on a modifed leaky aquifer concept with an unconfined aquitard above an anisotropic deeper fracture aquifer. The water level variations in the aquitard are also considered.

The ADI method is used in solving the finite difference equations. The model is calibrated using regional water level observations over one year. The calibrated model is used to obtain the regional distribution of safe yield over the $24,200 \mathrm{~km}^{2}$ area. Regions 


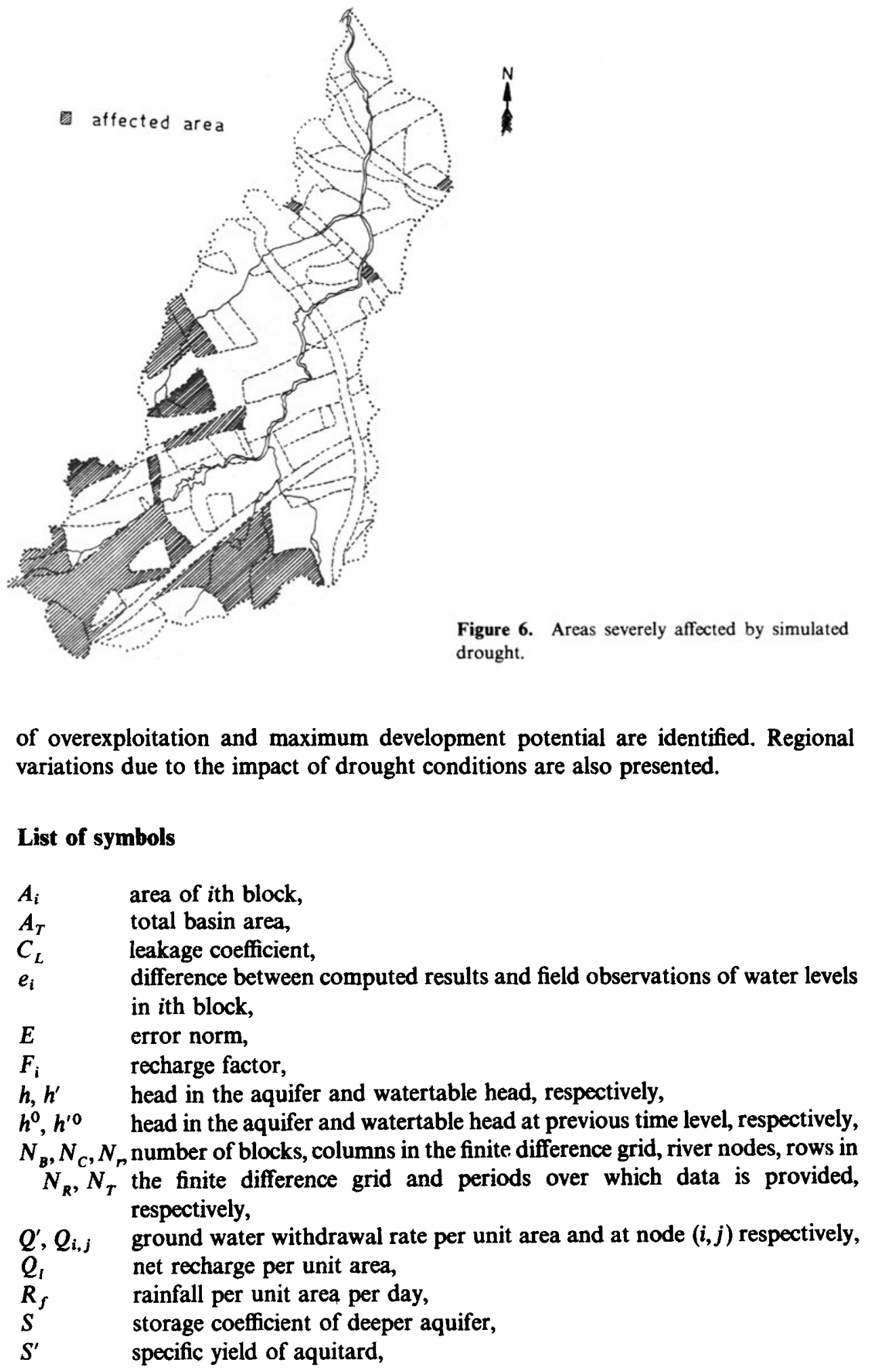


$T_{x}, T_{y} \quad$ transmissivities in the $x$ direction and in the $y$ direction, respectively, $x, y \quad$ coordinate directions in plan, northeast-southwest and northwestsoutheast, respectively,

$\Delta x, \Delta t \quad$ space and time steps.

\section{References}

Manvinder Singh 1978 Numerical modelling for confined aquifer M E dissertation, Indian Institute of Science, Bangalore

Nallasamy M 1975 Numerical studies on laminar internal separated flows Ph.D thesis, Indian Institute of Science, Bangalore

Prickett T A, Lonnquist C G 1971 Selected digital computer techniques for ground water resource evaluation, Bulletin 55, Illinois State Water Survey, Urbana, USA

Remson I, Hornberger G M, Molz F J 1971 Numerical methods in subsurface hydrology (New York: Wiley Interscience)

Sarma K V N, Sridharan K, Achutha Rao A, Sarma C S S 1986 Sādhanā 9: $31-42$

Stone H L 1968 SIAM J. Numer. Anal. 5: 530-558

Trescott P C, Larson S P 1977 Water Resour. Res. 13: 125-136 